\title{
Penerapan Metode Small Group Discussion Terhadap Motivasi Belajar Siswa
}

\author{
Kamaluddin H. Ahmad', Siti Nurma²
}

\footnotetext{
${ }^{1}$ Pendidikan Pancasila dan Kewarganegaraan, Universitas Muhammadiyah Mataram, Email: kamaluddin@gmail.com

${ }^{2}$ Pendidikan Pancasila dan Kewarganegaraan Universitas Muhammadiyah Mataram, Email: nhurmasitio@gmail.com
}

\begin{tabular}{l}
\hline INFO ARTIKEL \\
\hline Riwayat Artikel: \\
Diterima: 09 \\
Februari 2020 \\
Disetujui: 27 Maret \\
2020 \\
\hline
\end{tabular}

\section{Kata Kunci:}

Pembelajaran

Small Group

Discussion

Motivasi

Belajar Siswa

\begin{abstract}
Abstrak: Kurangnya minat atau motivasi belajar siswa pada mata pelajaran Pendidikan Pancasila dan Kewarganegaraan dikarenakan beberapa hal. Diantaranya; media pembelajaran yang digunakan guru kurang optimal, rendahnya motivasi belajar siswa membuat menurunnya prestasi. Tujuan penelitian ini adalah untuk mengetahui pengarauh pembelajaran metode small group discussion terhadap motivasi belajar. Pembelajaran small group discussion, small berarti kecil, group berarti kelompok, dan discussion berarti bertukar pikiran dan pendapat. Sehingga dapat disimpulkan bahwa small group discussion adalah tukar pendapat untuk memecahkan suatu masalah/mencari kebenaran di dalam kelompok kecil. Metode penelitian yang digunakan adalah penelitian kuantitatif, dengan sampel penelitian berjumlah 36 orang siswa, teknik pengumpulan data yang digunakan yakni observasi, angket dan dokumentasi. Sedangkan teknik analisis data yang digunakan adalah metode analisis deskriptif dan analisis regresi satu predokator. Hasil penelitian menunjukkan bahwa penerapan metode small group discussion terhadap motivasi belajar siswa dapat mempengaruhi motivasi siswa. Jadi adanya metode tersebut sangat membantu antusias siswa untuk belajar semakin giat dan aktif.
\end{abstract}

\begin{abstract}
Lack of interest or motivation to study students on the subjects of Pancasila education and citizenship due to several matters. Learning media that teachers use is less than optimal, the lack of motivation to learn students makes the achievement decrease. The purpose of this research is to know the Learauh of small group discussion of learning motivation. Small group discussion, small means little, group means group, and discussion means exchanging thoughts and opinions. So it can be concluded that small group discussion is an opinion exchange to solve a problem/find the truth in small groups. The research method used is quantitative research, with research samples amounting to 36 students, data collection techniques used are observation, polls, and documentation. While the data analysis techniques used are methods of descriptive analysis and regression analysis of one dozer. The results showed that the implementation of small group discussion methods of learning motivation for students could influence the students' motivation. So there is a method that helps students enthusiastically to learn more and more actively.
\end{abstract}

\section{A. LATAR BELAKANG}

Undang-Undang No. 20 tahun 2003 tentang Sistem Pendidikan Nasional Pasal 1 ayat (1) menjelaskan bahwa pendidikan adalah usaha sadar dan terencana untuk mewujudkan suasana belajar dan proses pembelajaran agar perserta didik secara aktif mengembangkan pontensi dirinya untuk memiliki kekuatan spiritual keagamaan, pengendalian diri, kepribadian, kecerdasan, akhak mulia serta keterampilan yang diperlukan dirinya, masyarakat, bangsa, dan Negara[1]. Tercapainya suatu tujuan pembelajaran yang diharapkan maka perencanaan kegiatan pembelajaraan seharusnya tidak tergantung semata-mata hanya pada guru, tetapi harus mengoptimalkan potensi yang dimiliki siswa. Namun kenyataan yang terjadi masalah motivasi belajar siswa menurun dipengaruhi kurangnya berbagai variasi model pembelajaran yang digunakan guru.
Hasil observasi ternyata motivasi belajar siswa masih rendah karena masih menggunakan metode pembelajaran ceramah sehingga siswa merasa bosan, jenuh dan hanya guru yang berperan aktif, sedangkan siswa hanya mendengar dan menulis apa yang disampaikan oleh gurunya, sehingga motivasi siswa untuk belajar sangat rendah. Standar KKM siswa mencapai 70 dari standard kelulusan mencapai 75 .

Salah satu cara mengoptimalkan pontesi siswa yang dimiliki oleh sisiwa dalam kegiatan pembelajaran adalah dengan melibatkan siswa berperan aktif dalam proses pembelajaran. Keaktifan siswa berperan penting dalam mendorong siswa untuk melakukan berbagai aktivitas pembelajaran di kelas, sehingga dapat menumbuhkan dan memperkuatkan pemahaman tentang materi pelajaran khususnya mata pelajaran Pendidikan Pancasila dan Kewarganegaran, namun kenyataannya proses pembelajaran belum sesuai dengan apa yang 
diharapkan, dikarenakan pada umumnya masih bersifat konvesional dengan menempatkan guru sebagai satusatunya sumber belajar. Seorang guru lebih sering menggunakan metode ceramah tanpa diselingi dengan metode pembelajaran, sehingga menyebabkan siswa menjadi pasif dengan hanya menerima materi penjelasan dari guru tanpa ikut berperan aktif dalam proses pembelajaran, dan menimbulkan rendahnya motivasi siswa serta tingkat keperhatian siswa terhadap materi pelajaran menjadi rendah.

Penelitian ini di dasarkan atas penelitian yang menerapkan metode pembelajaran small group discussion, di mana peningkatan dapat dilihat dari skor persentase observasi aktivitas belajar pada kompetensi dasar jurnal penyesuaian yang dilakukan di SMK Muhammadiyah Kretek[2]. Penelitian selanjutnya menggunakan metode small group discussion dengan model cooperative cearning, berangkat dari permasalahan pembelajaran yang masih berpusat pada guru. Guru lebih banyak menggunakan metode ceramah sehingga siswa tidak menemukan sendiri materi pembelajaran yang hendak dicapai dalam pembelajaran[3]. Kedua penelitian di atas sama-sama berangkat dari permasalah pembelajaran yang berpusat pada guru. Penelitian pertama menerapkan metode small group discussion pada kompetensi dasar jurnal penyesuaian, sedangkan penelitian kedua menggunakan metode small group discussion dengan model cooperative cearning. Hal tersebut dilakukan sebagai upaya meningkatkan motivasi belajar siswa.

Hal lain yang belum diungkapkan adalah karakteristik materi pendidikan kewarganegaraan yang kontekstual sehingga siswa sulit memahaminya, kombinasi metode pembelajaran, penyediaan media pembelajaran, dan pembelajaran daring. Keempat hal itu, merupakan komponen yang diasumsikan dapat meningkatkan motivasi belajar siswa. Berbagai masalah yang diuraikan sebelumnya, tentunya membutuhkan solusi yang bisa ataupun dapat meningkatkan motivasi belajar siswa.

Motivasi belajar siswa dapat meningkat karena adanya konsep-konsep yang dibuatkan berbentuk peta atau alur materi pembelajaran dalam bidang pendidikan pancasila. Sedangkan hasil belajar siswa dapat meningkat karena model concept mapping dalam pelaksanaan pembelajaran menggunakan media karton untuk membuat peta konsep materi ajar agar siswa mudah memahami materi pembelajaran[4]. Lainnya sependapat, bahwa upaya meningkatkan motivasi belajar yang dilakukan pendidik [5] adalah 1) tujuan pembelajaran. 2) menyemangati motivasi siswa. 3) wujudkan belajar yang menyenangkan. 4) penyajian materi harus menarik, unik agar siswa suka dan tertarik. 5) pujilah setiap siswa yang berprestasi. 6) memberikan penilaian. 7) setiap tugas siswa harus diberikan komentar. 8) ciptakan persaingan dalam kelas.
Kedudukan motivasi terletak pada guru yang senantiasa memotivasi siswa dalam belajar, untuk itu munculnya motivasi pada siswa dipengaruhi oleh guru yang membangkitkan motivasi mereka sehingga belajar semakin semangat. Oleh karena itu motivasi baik intrinsik maupun ekstrinsik harus ada pada diri siswa sehingga tujuan pembelajaran yang sudah dirumuskan dapat tercapai secara optimal [6].

Kelebihan dari strategi small group discussion ini adalah metode diskusi dapat merangsang siswa untuk lebih kreatif khususnya dalam kegiatan belajar mengajar, dapat melatih untuk membiasakan diri bertukar pikiran dalam mengatasi setiap permasalahan serta dapat melatih siswa untuk dapat mengemukakan pendapat atau gagasan secara verbal, disamping itu, diskusi juga bisa melatih siswa untuk menghargai pendapat orang lain[7]. Metode Small Group Discussion (SGD) merupakan cara mengorganisasikan siswa dalam kelompok kecil, melibatkan siswa secara aktif dalam belajar dan dapat motivasi mereka, beberapa siswa akan sangat senang ketika menjelaskan idenya kepada yang lain, memberikan kesempatan kepada seluruh siswa dan menuntaskan materi dalam suasana lingkungan yang nyaman[8]. Metode Small Group Discussion dengan Model Cooperative Learning mampu merubah prestasi belajar siswa kearah yang lebih baik [2], demikian pula Metode Small Group Discussion mampu merubah prestasi belajar siswa kearah yang lebih baik [3]. Dalam pembelajaran metode Small Group Discussion ini dapat digunakan oleh dosen dalam melaksanakan Lesson Study, dalam implementasi mulai kegiatan Plan, Do dan refleksi. Plan berorientasi belajar aktif, inovatif kreatif dan komunikatif. Do dilakukan dengan orientasi pada proses pembelajaran. Refeksi dilakukan memberikan saran dan masukan pada saat proses pembelajaran mana aspek kelemahan dan kekuatan [9].

Demikian pula, pada pembelajaran pendidikan kewarganegaraan dapat meningkatkan motivasi belajar siswa. Halite sejalan dengan pendapat bahwa penggunaan metode Card Sort kolaborasi Small Group Disscussion dapat meningkatakan motivasi dan prestasi belajar siswa pada materi Perlindungan dan penegakan hak asasi manusia (HAM). Proses belajar mengajar diberikan dorongan dan motivasi-motivasi kepada siswa. Indicator yang diukur berupa bertanya dan berpendapat serta menjawab pertanyaan siswa pada materi Perlindungan dan penegakan hak asasi manusia (HAM) dengan menyarankan siswa berdiskusi dalam kelas dan diskusi kelompok untuk mengemukakan idenya dalam hal mendefinisikan konsep secara tepat [10].

Selain penggunaan metode bervariasi, guru dalam proses pembelajaran mempunyai peran yang sangat penting sumber belajar bagimanapun hebatnya kemajuan teknologi, peran guru yang sangat penting dalam dunia pendidikan[7]. Terutama guru Pendidkan Pancasila dan Kewarganegaraan harus menguasi berbagai macam metode dan teknik pembelajaran 
Pendidikan Pancasila dan Kewarganegaraan harus mampu menciptakan suasana belajar yang nyaman dan menyenangkan agar proses belajar mengajar dapat berlangsung dengan cepat dan baik, humor guru sangat penting dalam proses pembelajaran, tetapi jangan sampai mengurangi inti pembelajaran itu sendiri.

Berbagai riset sebelumnya, bahwa dalam menerapkan Small Group Discussion menghasilkan berbagai temuan yang secara umum menjelaskan sebagian mereka menemukan ada pengaruh variable depende terhedap independen dengan berbagai mata pelajaran, penggunaan media pembelajaran dan lainya. Dengan melihat sifat ilmu pengetahuan yang tidak terbatas, untuk itu hasil penelitian itu dapat diujicoba lagi dengan metode yang sama tetapi tempat yang berbeda, sampel berbeda dan waktu yang berbeda itu hasilnya akan berbeda pula. Dengan sifatnya keilmuan yang tidak berbatas, maka penelitian ini penting dilakukan pada sisi pengembangan metode Small Group Discussion kearah yang semakin sempurna sehingga outputnya akan bermanfaat bagi guru maupun siswa. Untuk itu, artikel ini menjelaskan hasil kegiatan penerapan metode Small Group Discussion terhadap motivasi belajar siswa pada mata pelajaran PPKn kelas VIII di MTs Al-Raisiyah Mataram. Tujuan paper ini untuk menjelaskan pengaruh strategi pembelajaran Small Group Discussion terhadap motivasi belajar siswa pada mata pelajaran PPKn kelas VIII di MTs Al-Raisiyah Mataram.

\section{B. METODE PENELITIAN}

\section{1) Metode dan Pendekatan Penelitian}

Metode penelitian yang digunakan dalam penelitian ini adalah metode kuantitatif. Data yang diamati dengan metode kuantitatif yakni tentang pengaruh strategi pembelajaran small group discussion terhadap motivasi belajar siswa pada mata pelajaran PPKn di kelas VIII MTs Al-Raisiyah Maratam. Sementara pendekatan penelitian menggunakan eksperimen quasi.

Gambar 1. Desain Eksperimen Quasi

$$
\left(\begin{array}{lll}
01 & X & 02
\end{array}\right)
$$

Rancangan satu kelompok praperlakuan dan pascaperlakuan (One-group pretest -posttest design).

\section{2) Penentuan Subyek Penelitian \\ a. Populasi Penelitian}

Populasi di sini wilayah generalisasi yang terdiri atas subyek yang mempunyai kualitas dan karakteristik tertentu yang ditetapkan oleh peneliti untuk di pelajari dan kemudian ditarik kesimpulnya. Populasi bukan hanya orang, tetapi juga bisa organisasi, hasil karya manusia, dan benda-benda alam lainnya. Dalam penelitian ini populasi terdiri dari seluruh Siswa Kelas VIII di MTs Al-Raisiyah Mataram yang berjumlah 40 siswa. Jumlah tersebut tersebar di 2 (dua) kelas dengan rincian masing-masing kelas, sebagaimana dapat dilihat pada tabel berikut.

Tabel 1

Data Siswa Kelas VIII MTs Al-Raisiyah

\begin{tabular}{cccc}
\hline \multirow{2}{*}{ Kelas } & \multicolumn{2}{c}{ Jenis kelamin } & \multirow{2}{*}{ Jumlah } \\
\cline { 2 - 3 } & Laki-laki & Perempuan & \\
\hline VIII $^{\mathrm{a}}$ & 8 & 12 & 20 \\
VIII $^{\mathrm{b}}$ & 10 & 10 & 20 \\
\hline Jumlah & 18 & 22 & 40 \\
\hline
\end{tabular}

\section{b. Sampel Penelitian}

Sampel di sini sebagian dari populsi yang dipilih oleh peneliti sebagai wakil dari populasi yang representatif yang dijadikan subyek dalam penelitian untuk memudahkan peneliti untuk mendapatkan dan mengumpulkan data di lokasi penelitian. Populasi berjumlah 40 dapat diambil 36 dari taraf signifikan $5 \%$. Sampel yang digunakan dalam penelitian ini adalah sebanyak 1 (kelas) yang ditentukan, peneliti menetapkan kelas VIIIa dan sebagai sampel penelitian yang dipilih dengan teknik simple random sampling. Jadi sampel yang digunakan adalah 36 orang siswa.

\section{c. Cara Pengambilan Sampel}

Penelitian menggunakan 36 sampel, sedangkan populasi penelitian berjumlah 40 orang karena menggunakan tabel signifikasi $5 \%$ sehingga dari 40 siswa menjadi 36. Selanjutnya peneliti membuat undian untuk mendapatkan sampel pertama. Setelah mendapatkan sample pertama, maka nomor yang terpilih dikembalikan lagi agar populasi tetap utuh sehingga sample berikutnya tetap sama dengan sampel pertama, langka tersebut kembali dilakukan hingga jumlah sampel memenuhi kebutuhan penelitian[11].

\section{3) Sumber Data Penelitian}

Ada dua (2) sumber data dalam penelitian ini, yaitu :

1) Sumber Data Primer

Data primer dalam penelitian ini data diperoleh dari informan (sumber data primer) melalui proses kuesioner.

2) Sumber Data Sekunder

Sumber data yang digunakan dalam penelitian ini adalah sumber data primer dan sumber data sekunder, dimana data yang diperoleh penulis secara langsung dari obyek yang diteliti baik dari pribadi (responden) maupun dari suatu instansi yang mengelolah dengan cara melakukan kuesioner secara langsung dengan pihak-pihak yang berhubungan dengan penelitian, atau data yang diperoleh secara tidak langsung, artinya datadata tersebut berupa data kedua yang telah diolah lebih lanjut dan data yang disajikan oleh pihak lain. Data-data yang digunakan diperoleh dari laporan, jurnal-jurnal yang berhubungan dengan penelitian ini.

\section{4) Teknik Pengumpulan Data}

\section{a. Observasi}


Observasi dilakukan untuk mengamati siswa melalui angket motivasi, dan guru pada saat kegiatan pembelajaran dengan penerapan strategi small group discussion.

\section{b. Angket}

Angket yang digunakan dalama penelitian ini berupa formulir-formulir yang berisi pertanyaanpertanyaan yang diajukan secara terulis pada seseorang atau orang sekumpulan orang. Jumlah angket yang digunakan dalam penelitian adalah 30 .

\section{c. Dokumentasi}

Dokumentasi digunakan untuk memperoleh data penelitian yang berkaitan dengan.

a. Data keadaan siswa MTs Al-Raisiyah Mataram.

b. Data keadaan Guru, Pegawai dan Karyawan MTs Al-

Raisiyah Mataram

c. Keadaan saranan dan prasarana MTs Al-Raisiyah Mataram.

\section{d. Instrumen Penelitian}

Instrumen penelitian dilakukan pengujian validitas angket berkategori valid dan reliabilitas instrument berkategori baik.

\section{5) Teknik Analisis Data}

Teknik analisis data menggunakan analisis statistik deskriptif dan analisis regresi satu predikator atau rumus Product Moment, yaitu sebagai berikut:

$$
r_{x y}=\frac{N \sum X Y-\left(\sum X\right)\left(\sum Y\right)}{\sqrt{\left\{N \sum X^{2}-\left(\sum X\right)^{2}\right\}\left\{N \sum Y^{2}-\left(\sum Y\right)^{2}\right\}}}
$$

$$
\begin{aligned}
& \text { Keterangan : } \\
& \text { rxy }= \text { Koefisien korelasi antara variabel } X \\
& \text { dan variabel } Y . \\
& X Y= \text { Koefisien korelasi } \\
& \sum X \quad= \text { Jumlah skor nilai } X \\
& \sum Y \quad= \text { Jumlah skor nilai } Y \\
& \mathrm{~N} \quad= \text { Jumlah subjek yang diteliti[12]. }
\end{aligned}
$$

\section{HASIL PENELITIAN}

Pembelajaran penerapan Small Group Discussion terhadap motivasi belajar siswa pada mata pelajaran PPKn kelas VIII di MTs Al-Raisiyah Mataram dilaksanakan melalui tahapan persiapan, pelaksanaan dan evaluasi. Tahap persiapan mruapakan tahap awal yang dilakukan beruapa penyediaan perangkat pembe;ajaran seperti Silabus, RPP, Media pembelajara, ATK, dan instrument peenlitian. Tahap pelaksanaan yaitu melakukan ujicoba pree test kepada siswa untuk mengetahui valididitas dan reliabilitas angket yang sebarkan, selain itu juga pelaksanaan penelitian selama 1 bulan. Tahap evaluasi merupakan tahap akhir kegiatan pengambilan data dengan melakukan tes evaluasi sejauhmana pengaruh motivasi belajar terhadap pembelajaran Small Group Discussion. Adapun hasil penelitian diuraikan dalam bentuk gambar dan table.
Gambar 1.

Deskripsi Data Variabel X Terhadap Y

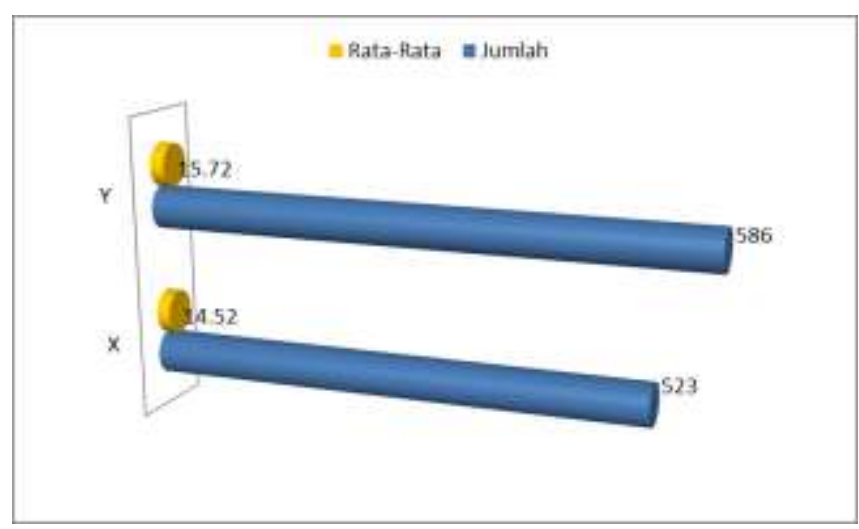

Hasil analisa dan data diolah yang telah dilakukan sesuai gambar 1 membuktikan bahwa ada pengaruh antara variable $\mathrm{X}$ terhadap Y yakni pembelajaran Small Group Discussion terhadap motivasi belajar siswa.

a. Analisis Data

1) Analisis statistik deskriptif

Merupakan data yang menentukan nilai mean, standar deviasi dan varians terhadap pengaruh Pembelajaran metode small group discussion terhadap motivasi belajar siswa pada mata pelajaran PPKn dikelas VIII MTs Al-Raisiyah Mataram rumus korelasi r product moment disajikan pada tabel di bawah ini.

Tabel 1

Hasil Analisis Deskriptif

\begin{tabular}{cccc}
\hline $\begin{array}{c}\text { Jumlah } \\
\text { siswa(N) }\end{array}$ & $\begin{array}{c}\text { Nilai rata- } \\
\text { rata atau } \\
\text { mean }\end{array}$ & $\begin{array}{c}\text { Standar } \\
\text { deviasi (S) }\end{array}$ & $\begin{array}{c}\text { Varians } \\
\left(\mathrm{s}^{2}\right)\end{array}$ \\
\hline 36 & 246,72 & 3,44 & 8,054 \\
\hline
\end{tabular}

2) Analisis Regresi satu predicator

Analisis regresi dapat dilakukan jika diantara kedua variabel akan dianalisiskan mempunyai kolerasi yang signifikan 5\% dapat dilihat pada tabel di bawah ini. Gambar 2

Hasil analisis Regresi pada variable $\mathrm{X}$ terhadap varibel $\mathrm{Y}$

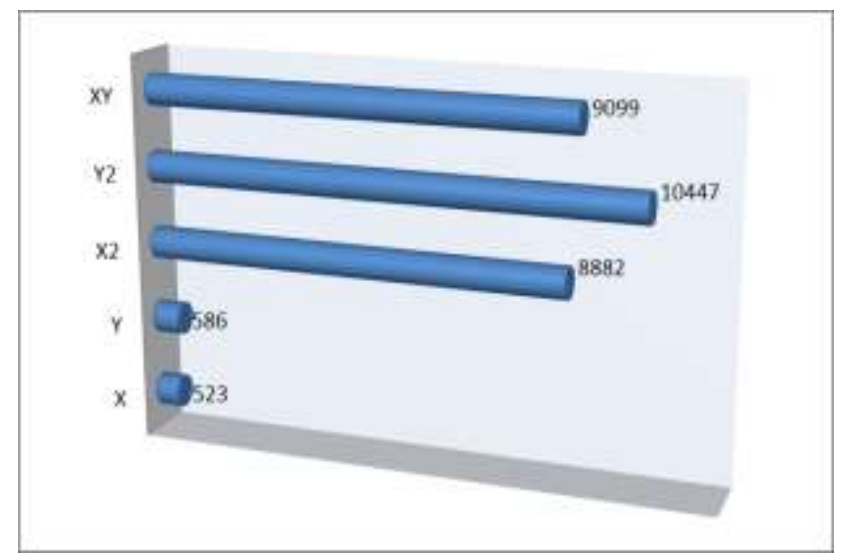

Untuk dapat membuat prediksi atau membuat persamaanya. ditempuh melalui berbagai perhitunganperhitungan yang dilakukan itu adalah sebagai berikut. 
a) Perhitungan korelasi antara variabel small group discussion ( $\mathrm{x}$ ) dan variabel motivasi belajar (y)

Memasukan data ke dalam rumus Koefisien korelasi r product moment yaitu sebagai berikut:

$$
\begin{gathered}
r_{x y}=\frac{N \sum X Y-\left(\sum X\right)\left(\sum Y\right)}{\sqrt{\left\{N \sum X^{2}-\left(\sum X\right)^{2}\right\}\left\{N \sum Y^{2}-\left(\sum Y\right)^{2}\right\}}} \\
36 x 9099-(523)(586)
\end{gathered}
$$

$\sqrt{36 \times 8882-(523)^{2}-36 x 10447-(586)^{2}}$
$\frac{327564-306478}{\sqrt{(319752-273529)(376092-343396)}}$

$\frac{21086}{\sqrt{(46223)(32696)}}$
$\frac{21086}{\sqrt{11511307208}}$
$=\underline{21086}$
38875,5
$=0,542$

b) Penguji hipotesis Ha dan Ho

Menguji signifikansi dengan t-hitung

t-hitung $=\frac{\mathrm{r} \sqrt{\mathrm{n}-2}}{\sqrt{1-\mathrm{r}^{2}}}=0,542 \frac{\sqrt{36-2}}{\sqrt{1-0,524 \times 0,542}}=\frac{3,16}{0,706}=4,475$

Kaidah pengujian:

Jika t-hitung $\geq$ t-tabel, maka Ho ditolak artinya signifikasi dan $\mathrm{t}$-hitung $\leq \mathrm{t}$-tabel maka Ho diterima dan Ha di tolak. Berdasarkan perhitungan di atas, $\alpha=0,05$ dan 36 uji satu pihak, $d b=n-2=36-2=34$, sehingga diperoleh t-tabel $=1,691$ ternyata t-hitung lebih besar dari pada t-tabel atau $4,475 \geq 1,691$ maka Ho ditolak, artinya ada pengaruh yang signifikasi pembelajaran small group discussion terhadap motivasi belajar siswa pada mata pelajaran PPKn dikelas VIII MTs al-raisiyah mataram.

c) Konsultasi koefisien padatabel nilair product moment

Berdasarkan uji signifikasi diatas pengaruh pembelajaran small group discussion terhadap motivasi belajar dengan deteminasi $\mathrm{r}^{2}=0,542^{2 \times} \times 100 \%=29,37$ artinya variabel small group discussion sebesar 29,37\% dan sisanya $70,63 \%$ dipengaruh oleh variabel lain.

\section{PEMBAHASAN}

Pembelajaran yang paling baik adalah pembelajaran yang melibatkan peserta didik agar mereka mampu mengajarkan materi yang diajarkan kepada orang lain. Sebagaimana yang dinyatakan[13] bahwa yang penting dalam proses belajar mengajar, guru sebagai pengajar tidak mendominasi kegiatan, tetapi menciptakan atmosfer belajar siswa serta memberikan motivasi dan bimbingan agar siswa mengembangkan potensi dan kreatifitasnya masingmasing. Perilaku guru akan berkorelasi positif dengan prestasi siswa jika mampu mengalokasikan dan menggunakan waktu dalam belajar[13]. Peserta didik yang dapat aktif, konsentrasi dan memahami materi yang disampaikan oleh pendidik atau guru kepada orang lain berarti dia sudah memahami dan menguasai materi tersebut dengan menggunakan model pembelajar small group discussion.

Pembelajaran small group discussion di MTs ALRaisiyah Mataram yang digunakan oleh peneliti bisa termotivasi belajar siswa dalam pembelajaran PPKn, Pembelajaran small group discussion mempunyai dampak positif dalam kegiatan pembelajaran karena terlihat dalam kegiatan diskusi siswa nampak lebih aktif dan semangat serta lebih paham terhadap materi yang telah disampaikan dalam melakukan diskusi dan bertukar pikiran dengan menggunakan pembelajaran bersama kelompok lain sehingga konsep- konsep yang ada dalam materi tersebut dapat dikuasai dengan baik. Sebagaimana hasil penelitian yang dilakukan Saraswati dan Djazari[2] bahwa peningkatan dapat dilihat dari skor persentase observasi aktivitas belajar pada kompetensi dasar jurnal penyesuaian pada tahap I yaitu 58,80 \% menjadi $85,22 \%$ pada tahap II. Demikian juga penelitian lainnya menjelaskan small group discussion dapat meningkatkan keaktifan belajar peserta didik [14]. Dalam pembelajaran small group discussion dapat meningkatkan hasil belajar dan keaktifan dapat diukur pada meningkatnya aktif bertanya, menjawab pertanyaan, berdiskusi, dan presentasi pada saat berjalannya pembelajaran [15].

Berbagai hasil penelitian tersebut sepada dnegan hasil penelitian kami, bahwa pembelajaran small group discussion merupakan model yang digunakan dalam pembelajaran dimana peserta didik saling bertukar pikiran untuk memecahkan suatu masalah dalam suatu kelompok kecil. Hasil analisa data penelitian menemukan adanya perbedaan yang sangat signifikan sebelum dan sesudah pembelajaran small group discussion berdasarkan hasil uji t yang telah dilakukan maka dapat disimpulkan terdapat perbedaan yang signifikansi $5 \%=\mathrm{t}$-hitung $=4,475 \geq \mathrm{t}$ tabel $=1,691$ jadi hipotesis yang diajukan atau hipotesis $\mathrm{Ha}$ diterima, berart ada pengaruh metode small group discussion terhadap motivasi belajar siswa pada mata pelajaran PPKn di kelas VIII MTs Al-Raisiyah Mataram. Dengan demikain adanya pembelajaran small group discussion 
sangatlah berpengaruh terhadap motivasi belajar siswa dengan determinasi adalah $29,37 \%$ dan sisinyan adalah 70,63\% itu di pengaruhi oleh variable yang lain.

Berdasarkan analisis dengan menggunakan rumus product moment dalam penelitian ini diketahaui nilai rtable sebesar 0,542 jauh lebih besar dari nilai tabel sebesar 0,329 dengan taraf signifikan 5\% dan nilai thitung sebesar 4,475 $\geq$ t- table 1,691 maka ada pengaruh yang signifikan pembelajaran metode small group discussion terhadap motivasi belajar siswa pada mata pelajaran PPKn di kelas VIII Mts Al-Raisiyah Mataram.

\section{E. SIMPULAN DAN SARAN}

Berdasarkan hasil analisis data dapat disimpulkan bahwa penerapan pembelajaran menggunakan metode small group discussion terhadap motivasi belajar siswa terdapat perbedaan yang sangat signifikan sebelum dan sesudah diberikan metode small group discussion. Hal tersebut terlihat pada hasil uji t taraf signifikansi $5 \%$ yaitu t-hitung 4,475 sedangkan $t$ tabel 1,691. Jadi Karena t-hitung lebih besar daripada $\mathrm{t}$ table maka hipotesis diterima. Jadi hipotesis yang diajukkan terbukti bahwa ada pengaruh metode small group discussion terhadap motivasi belajar siswa pada mata pelajaran ppkn di kelas VIII MTs Al-Raisiyah Mataram.

Berbagai hasil penelitian itu sangat bermanfaat untuk perbaikan system pendidikan di Indoensia. Untuk itu menyarankan kepada pemerhati pendidikan khususnya pemerintah untuk membuat kebijakan untuk guru agar bervariasi menggunakan metode pembelajaran sehingga dapat meningkatkan motivasi sisiwa.

\section{UCAPAN TERIMAKASIH}

Penulis mengucapkan terima kasih kepada Pihak Dinas Pendidikan Kota Mataram, Kepala Sekolah dan Guru MTs Al-Raisiyah Mataram yang telah banyak membantu dalam penyelesaian penelitian, sehingga artikel ini dapat disusun. Tak lupa penulis menyampaikan terimakasih kepada Tim Pengelola Civicus Universitas Muhammadiyah Mataram, semoga ke depan artikel ini bermanfaat untuk kemajuan pendidikan di Indonesia umumnya, dan Kota Mataram khususnya.

\section{DAFTAR RUJUKAN}

[1] R. Indonesia, "Undang-undang Republik Indonesia Nomor 20 tahun 2003 tentang Sistem Pendidikan Nasional," Jakarta Pemerintah Republik Indones., 2003.

[2] N. F. Saraswati and M. Djazari, "Implementasi Metode Pembelajaran Small Group Discussion Untuk Meningkatkan Aktivitas Belajar Pada Kompetensi Dasar Jurnal Penyesuaian Siswa Kelas X Akuntansi Smk Muhammadiyah Kretek Tahun Ajaran 2017/2018," J. Pendidik. Akunt. Indones., vol. 16, no. 2, pp. 15-23, 2018.

[3] A. Christiani, "Penerapan metode Small Group
Discussion dengan Model Cooperative Learning untuk meningkatkan Hasil Belajar siswa di Sekolah Dasar," J. Penelit. Pendidik. Guru Sekol. Dasar, vol. 2, no. 2, pp. 1-11, 2014.

[4] A. Sakban and K. Aini, "Penerapan Model Pembelajaran Concept Mapping Untuk Meningkatkan Motivasi dan Prestasi Belajar PKn Pada Siswa Kelas V MI NW Apitaik Lombok Timur Tahun Pelajaran 2015/2016," Civ. Pendidikan-Penelitian-Pengabdian Pendidik. Pancasila dan Kewarganegaraan, vol. 4, no. 1, pp. 123-128, 2016.

[5] S. Suprihatin, "Upaya guru dalam meningkatkan motivasi belajar siswa," J. Pendidik. Ekon. UM Metro, vol. 3, no. 1, pp. 73-82, 2015.

[6] A. Emda, "Kedudukan motivasi belajar siswa dalam pembelajaran," Lantanida J., vol. 5, no. 2, pp. 172-182, 2018.

[7] W. Sanjaya, "Strategi pembelajaran berorientasi standar proses pendidikan," 2006.

[8] P. Fathurrohman and M. S. Sutikno, "Strategi Belajar Mengajar Melalui Penanaman Konsep Umum \& Konsep Islami," 2019.

[9] M. Wiharto, "Kegiatan Lesson Study Dalam Pembelajaran,” FGD-Pengayaan Pengemb. Kurikulum Pendidik. Tinggi. Kementrian Ris. Teknol. dan Pendidik. Tinggi, pp. 22-30, 2017.

[10] A. Aisah, N. Suryani, and S. S. Fadhilah, "Penerapan Strategi Pembelajaran Card Sort Kolaborasi Small Group Discussion Sebagai Upaya Meningkatkan Motivasi dan Prestasi Belajar Pendidikan Kewarganegaraan," Teknodika, vol. 16, no. 1, pp. 1-9.

[11] M. Anshori and S. Iswati, "Metodologi penelitian kuantitatif," Surabaya Pus. Pnb. dan Percetakan UNAIR, 2009.

[12] A. Suharsimi, "Dasar-dasar Evaluasi Pendidikan Edisi 2," Jakarta PT Bumi Aksara, 2013.

[13] M. Fathurrohman, "Model-Model Pembelajaran." Jogjakarta: Ar-Ruzz Media, 2015.

[14] E. S. N. Jannah, "Penerapan Metode Pembelajaran 'Active Learning-Small Group Discussion' di Perguruan Tinggi Sebagai Upaya Peningkatan Proses Pembelajaran,” FONDATIA, vol. 3, no. 2, pp. 19-34, 2019.

[15] W. Putriawati, "Penerapan Metode Pembelajaran Small Group Discussion untuk Meningkatkan Hasil Belajar dan Keaktifan Mahasiswa," Prism. Sains J. Pengkaj. Ilmu dan Pembelajaran Mat. dan IPA IKIP Mataram, vol. 7, no. 1, pp. 80-90, 2019. 